\title{
Research on Inheritance and Marketization Development of Harbin Wheat Straw Painting Artware
}

\author{
Xue Jiang \\ School of Design Art \\ Harbin University of Commerce \\ Harbin, Heilongjiang, China
}

\begin{abstract}
Harbin wheat straw painting artware has unique manifestation pattern with exclusive regional style and features of north. With marketization development in recent years and gradually prosperous development of tourism, systematic development and design of artware with regional features can not only push forward development of local economy, but also promote tourism culture propaganda. This paper will deeply analyze and discuss how to solve the problems of singular design thought, lack of regional features and low market value of Harbin wheat straw artware, thus improving design taste of Harbin wheat straw products and facilitating its benign marketization development.
\end{abstract}

Keywords-wheat straw artware; marketization; Harbin artware

\section{INTRODUCTION}

On December 3, 2014, Ministry of Culture of China announced that Harbin wheat straw barbola is selected in national intangible cultural heritage register. Approval of national intangible cultural heritage makes this artwork with northeastern folklore characteristics enter our sight.

\section{ORIGIN AND ART FORM OF WHEAT STRAW PAINTING ARTWARE}

Wheat straw painting has a long history. China is a great power of agriculture and it is famous for producing grain in the world. As early as in the Eastern Han Dynasty, wheat straw is made into painting for worship in royal court. People at that time regard wheat as auspicious grass praying lucky fortune. Therefore, wheat straw painting is regarded as worship of totem culture. As treasure of traditional folk art, wheat straw painting has simple style of art and its styling features originate from life. So it is vivid and interesting. It has a broad range of topics, like a harmonious union lasting a hundred years, peony of flourishing age, fruitfulness, agricultural fun in the field and so on. Drawn patterns are vivid. Fierce tiger is majestic-looking with irresistible advance. Peony owns national beauty and heavenly fragrance and it is the victor among various kinds of flowers. Fleeing horse in stampede raises its head and neighs with magnificence. Landscape in paintings is immersive and we seem to hear the sound of flowers, birds, fishes and insects in the painting.

Subject and content of traditional wheat straw painting originate from life. It is true reflection of common people's hometown and labor harvest in countryside field, it is close to people's life in a great extent and many paintings are direct description of real life. Therefore, it is a kind of brisk art form which spreads in the fork all the time. As a kind of folk art form, wheat straw painting's main function is aesthetic appreciation instead of seeking of art, just like other folk art. It is a kind of art existence for beauty. Therefore, it lays the roots in folk and has a history of more than two thousand years. Traditional wheat straw painters obtain inspiration from ordinary life and get enlightenment of beauty. Then, they reproduce artistic image of this kind of beauty with wheat straw as the manifestation pattern.

In Leo Tolstoy's Art Theory, definition of art and beauty is: "Art is the tool of exchanging sense of beauty". It is a kind of art form of recreating by oneself for folk artists to make wheat straw paintings slack season of agriculture. As time passes, they will give works to relatives, friends and neighbors as presents, facilitating development and propagation of this art form. However, unspecialized existence makes wheat straw painting have no school or system, thus it fails to spread widely and has no scale in existence. What's more, it has no great achievement in China's arts and crafts history.

In 1960s, handicraft manage hall of Heilongjiang Province successively selects a batch of excellent art youth in Harbin, Tsitsihar, Mutankiang, Kiamusze and so on to go to Fujian, Shandong, Zhejiang, Shanxi and so on to learn wheat straw painting. They adhere to the principle of "learn inside and create outside" and adopt the mode of "master instructing apprentice" to reform and innovate wheat straw painting. The craft artists of old generation exert their utmost effort to research ancient wheat straw process technology, conduct bold innovative practice, and summarize a set of wheat straw painting making procedure with Harbin features, making the folk treasure of wheat straw painting reappear in front of the public.

Craft picture made from wheat straw begins in 1970s and it is one of the initiative varieties of Harbin industrial arts factory. 
It imitates folk paper cut techniques and special skills of craft, creates unique craft of foil stamping, dyeing, roughening and matting on the basis of application of cutting and carving, adopts technique of depth embossment and forms unique art style.

Harbin wheat straw painting has complete specification and variety and a wide range of rich materials with strong expressive force. Thus, it has a high reputation in domestic and foreign market. With development of the era, wheat straw artware develops rapidly on the basis of Harbin wheat straw painting in 1980s. It combines wheat straw painting with pure appreciation function with characteristics of artware and yields unusually brilliant results in domestic and foreign market. In 1982, Ta Kung Pao, a famous newspaper of Hong Kong, has related long report on producing features and development of wheat straw artware. Wheat straw artware has been sold to America, Britain, Japan, Malaysia, Thailand and so on, a dozen countries and regions in total. It wins agreed good reputation from numerous traveling merchants. Wheat straw artware has both aesthetic nature and practicability and it is a good choice as festival gift and home decoration. Product modeling and style are various with rich colors. As to decorative patterns, it usually adopts traditional Chinese painting, oil painting, craft painting and so on with rich decorativeness and elegant style and appearance.

On the left side of first floor lobby of Harbin friendship palace hotel, there is a three-dimensional wheat straw painting -- Sungkiang Wetland on the wall. It is 12.5 meters long and 4.5 meters wide. It is one of the most excellent wheat straw paintings in China, and it can be called a masterpiece. A dozen craft artists spend more than 20 nights on producing it. Its value is more than 200 thousand yuan. It can be called peak works of Harbin arts and crafts. Reed swaying with the wind under blue sky and around clear water on wetland ripples. Lifelike beautiful scenery attracts every guest entering into the hall.

In 2012, Man's World Full of Fragrance taking lilac as prototype and Tiger Head taking manchurian tiger as theme cause a sensation on exhibition in Taiwan. Vivid gradual change of color of lilac's petal, natural gloss of animal fur and even metallic bronze ware make Taiwan peer exclaim in great surprise. They exclaim: "How could ordinary wheat straw make such vivid products!" In the same year, Lien Chan gets wheat straw painting of Manchurian Tiger as a gift during his visit in Harbin and he likes it a lot.

\section{Market Problems Faced by Harbin Wheat StraW ARTWARE IN FAST RETAILING ERA}

In current fast retailing era with rapid development of marketization, consumers usually won't regard the work of art made slowly as treasure. Through market survey, we find that many merchants managing tourism artware say that, when choosing to buy tourist souvenir currently, most tourist guests from other places and young consumption group firstly see whether the style is novel and attracts people instead of paying attention to whether the artware is hand-made with certain commemorate value and significance. Compared with artistry, they pay more attention to appearance and practicability. At the same time, consumers are sensitive about price. Generally speaking, souvenir at the price of dozens of yuan sells best. Hand-made artware with high price can not win love from most tourists.

According to above consumption features, print pictures of tourist attractions with Harbin features onto ordinary artware cinnabar or crystal set-up and this kind of artware will sell much better with extremely simply reform. Southern tourists usually like crystal set-up products like ice engraving while Russian tourists love fridge magnet with Harbin element.

It is actually a consumption misunderstanding of consumers to regard products with Harbin scenery as Harbin artware. It can just be counted as a kind of simple artware and it can not replace traditional hand-made artware at all. Although this kind of artware made by machine has large market shares, it can not compete with traditional pure handmade artwork.

It is a misunderstanding of tourists and consumers to regard products with pictures of Harbin tourism scenery as artware with Harbin features. This kind of product can not replace traditional hand-made artware of Harbin. This kind of products with quantity production can not compete with traditional hand-made art ware.

An ordinary wheat straw paper needs fuming, steaming, ironing, bleaching and dissecting of wheat straw by handicraftsman and working procedure of striking off and brush coating before sticking them on oil seal paper piece by piece; It takes at least 10 days to complete a palm center sized squirrel from carving model to ripping paper, roughening and sticking piece by piece; It takes a month to complete a squirrel painting of 10 cun from design to underpainting and sticking. It needs a dozen craftsmen's cooperation to make a wheat straw painting out of ordinary wheat straw. A handiwork "product" is artwork while it only takes a few minutes for a machine to make a one-time profiled product. The latter can just be called artware at most. Although wheat straw painting is far better than that of copy in terms of artistic effect, producer and consumer obviously lose their patience in the fast retailing era.

It is abnormal to support an industry by relying on one or two enterprises. Behind the product with high reputation, there are many people making efforts in this industry. For instance, dark-red enameled pottery of Yixing, china of Jingdezhen, Jiangxi, small commodities of Yiwu and Sichuan brocade in Chengdu are produced by many local enterprises. Although quality is uneven, this industry has great popularity and it is tightly grasped in its own hand.

Nowadays, most of industrial artists of the first and the second generally are not longer alive, and the number of artists from third generation to eighth generation is at least 10 thousand. With their gradual passing away, northeast traditional arts and crafts works are facing the danger of lost in transmission.

Arts and crafts of Heilongjiang haven't form an industrial chain and still stay in planned economy era. In order to change current status, firstly, the government needs to intensify policy support, clearly define industrial location and lead more 
powerful enterprise into this field to make one thriving branch become various families blooming.

In Canton fair, artware develops towards practical furniture decoration direction increasingly and more life elements are infused in works. There is hand bass, dressing case and brush pot made by wheat straw. Nowadays, liberating wheat straw from painting and creating more practical wheat straw works which are closer to life is development direction of wheat straw painting.

\section{INHERITANCE AND MARKETIZATION DEVELOPMENT OF HARBIN WHEAT STRAW PAINTING ARTWARE}

Through research and survey, we know that current lack of talents leads to original design of wheat straw painting being out of stock. Many people understand computer design, but few talents can design works according to characteristics of wheat straw painting. In recent 30 years, people's life is increasingly rich and colorful, but originality theme is less and less. A large number of repeat works make Harbin wheat straw artworks facing the difficult problem of withered creation. "In recent years, wheat straw paintings which can be taken out are Manchurian Tiger, Lilac, Crane and architectural scenery. There are less and less works with connotation and artistic expressive force."

Artware systematic development and design with regional features can facilitate development of local economy and tourism culture propaganda. Deeply analyze and discuss solutions to problems of singular thought, lack of territory and low market value of Harbin wheat straw artware in order to improve design taste and facilitate benign marketization development of Harbin wheat straw products.

- Use digital technology to protect inheritance of Harbin wheat straw artware. Adopt digital recording, digital photography, digital synthesis two-dimensional scanning, three-dimensional stereoscanning and graph and image processing and other techniques to collect making process and other information of Harbin wheat straw painting's inheritor comprehensively and wholly with high precision. Establish digital information file and save according to classification in order to provide accurate digital information material for research, study, appreciation, exploitation and application in future.

- Use big data technique to analyze order trend of Harbin wheat straw painting and features of order variety, thus serving research and development and designing new products better.

- Design, research and develop, and produce tourism souvenir with Harbin regional features with support of college's teaching advantage and excellent design team, and let students apply their knowledge and make innovative design, thus forging good inheritance of this endangered artistry and facilitating employment of local college students majoring in arts. At present, there are many old process masters who are out of work. Besides, major of art design in colleges of Harbin develops rapidly right now. We can rely on college's design advantage and cooperate with these old masters having technique advantages to form effective industrial chain production mode. Thus, we can effectively help establish tourism image of Harbin, add fresh blood to college's design education and characteristic development of teaching, and forge benign inheritance of this art.

- Use combination of traditional material and new process or new material and traditional process to improve and innovate Harbin wheat straw painting artware. For instance, Ma Wenxia, a famous wheat straw artware great master in Harbin, and his teach have ever independently researched and developed several patents for invention. Among them, roughening process replaces previous choke process. Improvement of this technique saves half of producing time of wheat straw artware and injects innovative elements of this era into wheat straw art ware.

- Set booth for producing of Harbin wheat straw artware in some famous tourist attractions of Harbin to make it available for domestic and foreign tourists to know about design and producing process of wheat straw artware and participate in producing process of wheat straw painting artware. Thus, it can have good effect on propaganda of Harbin wheat straw artware and satisfy tourists' curiosity, thus providing effective solutions to promotion of marketization development of Harbin wheat straw artware and increasing marketing and sales of Harbin wheat straw artware.

\section{CONCLUSION}

According to requirement of marketization development in fast retailing era, use advanced digital technology and big data technology to protect and inherit producing of traditional wheat straw painting and artware. Inject modern design elements into Harbin wheat straw artware from the aspects of modeling, color, patter, variety and so on, and design wheat straw artware which can adapt to marketization development with Harbin features. Look for bigger development chances for Harbin wheat straw painting artware and make great efforts to take a leading step in fierce market competition.

\section{REFERENCES}

[1] Liu Chen. Chinese Traditional Handicraft with Beautiful Material and Smart Process-Analysis on Aesthetic Value of Wheat Straw Painting, Popular Literature 2011-10-25.

[2] Liu Yang. Research on Heilongjiang Wheat Straw Arts and Crafts. Harbin Normal University 2013-06-25.

[3] Xie Ping. New Excellence in Black Soil Culture Miracle Longjiang Excelling Nature. Heilongjiang Daily 2011-06-11. 